\title{
Enhanced ZRP Protocol for Mobile Ad-hoc Networks
}

\author{
M.N Sree Ranga Raju \\ Dept. of Telecommunication. Engg. \\ Bangalore Institute of Technology \\ Bangalore, Karnataka \\ India 560004 \\ mnsrrerediffmail. com
}

\author{
Dr. Jitendranath Mungara Ph.D \\ CMR Institute of Technology \\ Banglore, Karnataka \\ India 560064 \\ jmungara@yahoo.com
}

\begin{abstract}
Mobile Adhoc Network(MANET) is the collection of independent mobile nodes that can communicate to each other via radio waves. The mobile nodes that are in radio range of each other can directly communicate, whereas others need the aid of intermediate nodes to route their packets. These networks are fully distributed and can work at any place without the help of any infrastructure. This property makes these networks highly exile and robust. There are many protocols which are proposed on the issues of MANET but they have not considered all possibility of routing in intra as well as inter zone. The main motto of the research is upgrading the existing ZRP Model with enhancement of namely MDVZRP, $S B Z R P, Q C S$ to achieve better performance. The design goals of ZRP enhancement are to enhance the performance in the area such as quick route reconfiguration, route acquisition delay, and low mobility scenarios considering the all possible way of routing in inter as well as intra zone.
\end{abstract}

\section{KEY WORDS:}

Routing, MANET, MDVZRP, SBZRP, QCS, ZRP.

\section{INTRODUCTION}

In ad hoc networks, nodes do not start out familiar with the topology of their networks; instead, they have to discover it. The basic idea is that a new node may announce its presence and should listen for announcements broadcast by its neighbors. Each node learns about nodes nearby and how to reach them, and may announce that it, too, can reach them by using some routing algorithms.

There are two approaches for routing algorithms called proactive and reactive. In proactive routing protocols attempt to continuously evaluate the routes within the network, so that when a packet needs to be forwarded, the route is already known and can be immediately used. The advantage of the proactive scheme is that, once a route is needed, there a little delay until the route is determined. Reactive protocols, invoke a route determination procedure on demand only. Thus, when a route is needed, some sort of global search procedure is employed. In case of reactive routing protocols, the delay to determine a route can be quite significant, as route information is not available in prior. This global search mechanism requires significant control traffi c. Because of this long delay and excessive control traffic, pure reactive routing protocols may not be applicable to real-time communication.

Hybrid routing combines the advantages of proactive and reactive routing protocols. Make use of advantages of proactive discovery within a nodes local neighborhood and reactive routing for communication between these neighborhoods. ZRP is a best suitable example for hybrid 
International Journal of Wireless \& Mobile Networks (IJWMN) Vol. 3, No. 4, August 2011

routing protocol. ZRP defines a zone around each node consisting of the nodes $\mathrm{k}$ neighborhood (that is, all nodes within $\mathrm{k}$ hops of the node). A proactive routing protocol, intra zone routing protocol (IARP), is used inside routing zones, and a reactive routing protocol, inter-zone routing protocol (IERP), is used between routing zones. A route to a destination within the local zone can be established from the sources proactively cached routing table by IARP. ZRP has been designed to run on the IP layer and relying on outside help for the detection of neighbors. It's not directly the ZRP itself that communicate over the network, but its different components that communicate by themselves. IERP is what will handle the updating of routing tables from its own research and road that have been imported by IARP.

There are other approaches for resolving routing issues in the ad hoc networks, such as Bordercast Resolution Protocol (BRP). BRP is included with the IERP in order to provide border casting services which do not exists in IP. In the current version of the BRP, the content of border cast message is considered to be accessible to any host which receives the message. The BRP keeps track of which nodes a query has been delivered to, so that it can prune the border cast tree of nodes that have already received (and relayed ) the query. When a node receives a query packet for a node that does not lie within its local routing zone, it constructs a bordercast tree so that it can forward the packet to its neighbors. These nodes, upon receiving the packet, reconstruct the bordercast tree so that they can determine whether or not it belongs to the tree of the sending node. If it does not, it continues the process and determines if the destination lies within its routing zone and taking the appropriate action, upon which the nodes within this zone are marked as covered.

The remainder of this paper is organized as follows; section 2 gives the survey of previous work related to different categories of vertical handoff. Section 3 discusses the proposed work that focuses on optimizing of dwell time and transmission power. The simulation of this work is designed in the section 4.Finally section 5 and 6 discusses about the simulated results and conclusion respectively.

\section{RELATED WORK}

This section reviews the some of literature pertaining to routing in wireless ad hoc networks. In [1], the work presents query controlled scheme to provide enhanced detection and prevention of overlapping queries. The work done in [2] presents a selective bordercasting zone routing protocol to reduce the network load by limiting the number of control packets when the protocol searches for new route. The work presented in [3], is a protocol called multipath distance vector zone routing protocol for mobile ad-hoc networks, which uses a topological map of the zone centered on a node to guarantee loop freedom and alternative paths in the case of route failure and disjoint paths. In [4] an algorithm is proposed to provide improved quality of service such as low end to end delay and high throughput via hybrid routing protocol ZRP. In paper [5] independent zone routing is proposed, which allows adaptive and distributed configuration for the optimal size of the each node's routing zone on the per node basis. $\operatorname{In}[6]$, it has given review about the current routing protocols in Ad-hoc networks.

In this paper [7], he has proposed the secure message trans-mission (SMT) protocol to safeguard the data transmission against arbitrary malicious behavior of network nodes. He suggest that SMT is a lightweight, yet very effective, protocol that can operate solely in an endto-end manner. It exploits the redundancy of multi-path routing and adapts its operation to remain efficient and effective even in highly adverse environments. Overall, the ability of the protocols to mitigate both malicious and benign faults allows fast and reliable data transport even in highly adverse network environments is given in work [8].

This [9] paper presents evidence that multipath routing can mask a substantial number of failures in the network compared to single path routing protocols and that the selection of paths according to DPSP can be beneficial for mobile ad hoc networks since it dramatically reduces the rate of route discoveries. In [10], it is proposed a solution to the managed-open scenario 
International Journal of Wireless \& Mobile Networks (IJWMN) Vol. 3, No. 4, August 2011

where no network infrastructure is pre-deployed, but a small amount of prior security coordination is expected, protocol suggests, authenticated routing for ad hoc networks (ARAN) and is based on certificates and successfully defeats all identified based link weights attacks. Authenticated Routing for Ad hoc Networks (ARAN), presented in [11] uses public-key cryptographic mechanisms to defeat all identified attacks. ARAN can secure routing in environments where nodes are authorized to participate but untrusted to cooperate, as well as environments where participants do not need to be authorized to participate.

In this paper [12], it is presented a protocol called Trustworthiness-based Quality Of Service (TQOS) routing, which includes secure route discovery, secure route setup, and trustworthiness-based QoS routing metrics. The routing control messages are secured by using both public and shared keys. The routing metrics are obtained by combing the requirements on the trustworthiness of the nodes in the network and the QoS of the links along a route. The simulation results shows the effectiveness of the proposed secure QoS routing protocol in both security and performance. In this paper[13], it is focused on the impact of rushing attack implemented by malicious nodes (MNs) on AODV routing protocol. The Simulation results shows that AODV protocol fails completely in presence of rushing attack. The work in [14] presents challenges and future of Ad-hoc networks.

\section{PROPOSED WORK}

In this section, we present an enhanced ZRP route computation scheme for wireless Ad-hoc networks. The standard protocol presented for Ad-hoc wireless network are MD-VZRP,SBZRP and QCS. In our work we have modified the existing ZRP protocol called as enhanced ZRP, which will be branched based on a selection parameter specified through the configuration . The new enhancements to the ZRP protocol in the areas like quick route reconfiguration, route acquisition delay, low mobility scenarios is implemented.

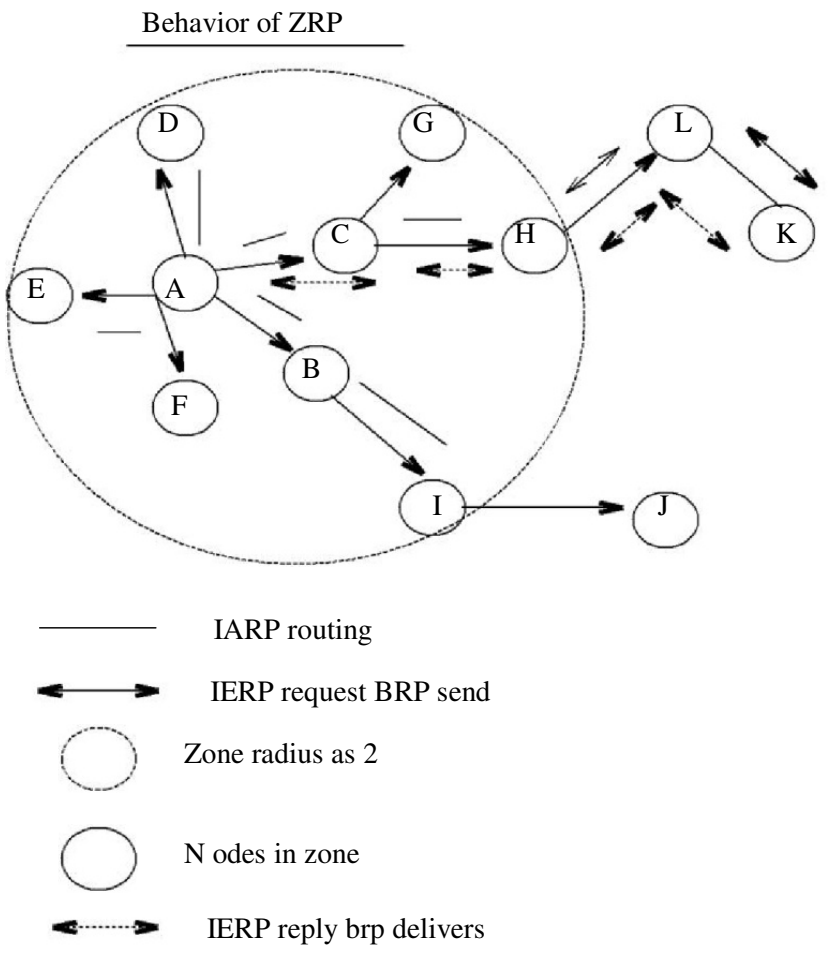

Fig. 1. Conceptual ZRP Behavior 
The model of standard ZRP is shown in figure 1, which has overlapping query messages. These messages will overload the system and degrade the system efficiency. Hence our query control mechanisms allow ZRP to provide routes to all accessible network nodes, with less control traffic than purely proactive link state or purely reactive route discovery, and with less delay than conventional flood searching.

In MDVZRP the nodes initiate the route discovery process to a specific destination, only if needed and not at available in its routing table. Therefore, MDVZRP discounts the number of route discovery to more than 3 times than a reactive protocol. Also when a link break in an active route is detected, MDVZRP uses the alternative path selection process instead of using the local route repair as in some reactive protocol. MDVZRP employs a full dump technique, in which the new node receives its nearest neighbors routing tables once joined the network and send a beacon to create its own routing table. This technique gives the new node ability to view the entire network rather than its zone only.

SBZRP reduces the network load by limiting the number of control packets when the protocol searches for a new route. When network load is high, the mean delay of ZRP is higher than SBZRP. This is because when the ZRP searches for a new route, the number of IERP RQP is increased, thus the node buffer is congested, which results in the increase of mean delay. When the node stops for a short period of time that means the moving degree is high, The SBZRP has higher link usability than a ZRP. When node moving degree is high, the route search failure becomes high. For the SBZRP, if the route search fails, a new route search starts from the failed node. Thus ,the new route search time is shorter than ZRP and the number of data sent to the destination node becomes high.

\section{Detection of Query Packet Id}

To reduce this delay we can go for query control mechanisms. Query detection uses query source node's Id and query Id pair. Below Fig. 1 depicts query detection scheme. Where ' $S$ ' is the source node and destination node ' $\mathrm{D}$ ' is not in S's local zone. Hence S bordercasts the query message packet. Nodes J, K, I detects the query packet through QID Method-1 and node $\mathrm{H}$ detects it through evesdropping i.e QID Method-2.

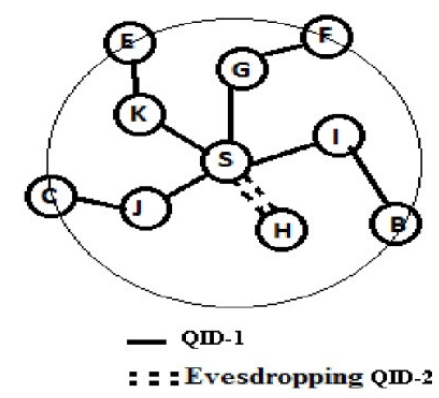

\section{Premature Node Termination}

With the knowledge of the QD obtained a procedure has to be followed in which covered nodes can be pruned by the bordercast tree. This procedure is known as premature node termination. By referring to below Fig. 2, we can see that node ' $S$ ' bordercasts the query message packet to its peripheral nodes. Node 'I' receives same copy of query message packet through bordercast tree by the other node as it may be interior member of other routing zone. Now 'I' searches for the interior zone member of other node, and uses QD to detect is it necessary to relay that query message packet or no. 'I' identifies that nodes are been covered, it reconstructs the bordercast tree. Prunes covered nodes from other node' bordercast tree and deletes the query message 
received by other node using the criterion called premature node termination.

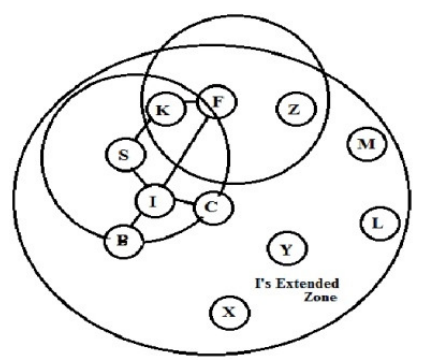

Fig. 2: Premature Node Termination

\section{Random Query Analysing and Processing Delay}

Bordercasting node initiates bordercasting to its peripheral nodes. We can observe from the below Fig. 3 that bordercasting node ' $S$ ' bordercasts the query message packet to peripheral node ' $F$ '. This node ' $F$ ' will border cast the query message packet to ' $X$ ' and ' $Y$ '. ' $X$ ' and ' $Y$ ' receive query at the same time. If both of them bordercasts the query then again there are chances that same node may relay the same query multiple times. Unless and untill $\mathrm{X}$ and $\mathrm{Y}$ check for the QD information they both will not be knowing that the query bordercasted by them is redundant.

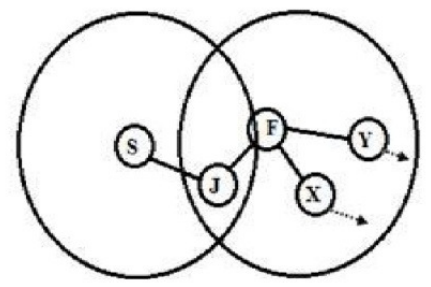

Fig. 3: Random Query Analyzing and Processing Delay

\section{Selective Bordercasting Approach:}

This approach is proposed for Minimisation of control overhead packets for ZRP protocol, Which leads to congestion and delay in route acquisition. The selective bordercasting mechanism use same IARP protocol as in ZRP, but use a new mechanism in IERP for interzone routing because the bordercasting procedure starts with IERP protocol.

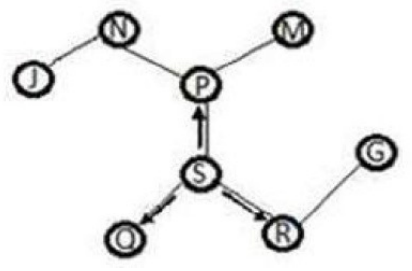

Fig. 4: IARP packet broadcasting.

The operation of the IARP is shown in Fig. 4. The source node $\mathrm{S}$ generates the IARP packet and broadcasts in its local routing zone, by using neighbor's information, the central node updates its routing table. When the destination is outside the routing zone, the interzone 
operation initializes. The IERP is slight different from IERP in original ZRP, to understand the mechanism of new IERP, consider the Fig. 5, which the route to the destination in unknown to the source. Then the IERP request packet is generated. The information in the new IERP packet is: $\mathrm{SN}=\mathrm{S}, \mathrm{DN}=\mathrm{D}$, and border-cast hop value $(\mathrm{BH})=1$ which is shown in Fig. 5(a) and Fig. 5(b). The generated IERP packet is sent to all border nodes which lie on the zone border, which have same zone radius.

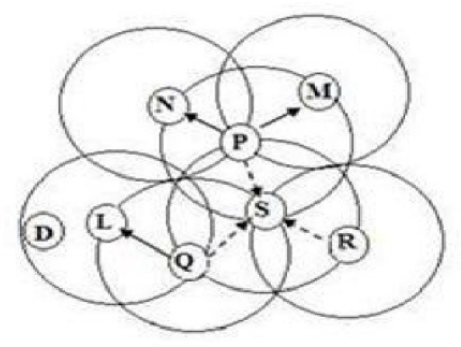

Fig. 5: IERP Packet transmission.

\begin{tabular}{|c|c|c|c|c|}
\hline DN & SN & $\begin{array}{c}\text { Intermediate } \\
\text { Node }\end{array}$ & $\begin{array}{c}\text { Packet } \\
\text { Type }\end{array}$ & BH \\
\hline
\end{tabular}

Fig. 5(a): IERP Packet format.

\begin{tabular}{|c|c|c|c|c|}
\hline DN & SN & $\begin{array}{c}\text { Intermediate } \\
\text { Node }\end{array}$ & $\begin{array}{c}\text { Packet } \\
\text { Type }\end{array}$ & $\mathrm{BH}$ \\
\hline D & S & Null & REQ & 1 \\
\hline
\end{tabular}

Fig. 5(b): IERP Request packet format of Fig. 5.

The nodes in the zone boundary which receives the IERP request packet with increase in the $\mathrm{BH}$ value by 1 . Then the node checks the destination in its routing table, if the destination address doesn't found in its routing table, then it should continue with the border casting procedure. When the nodes find the destination in its routing zone or itself a destination then the node will replays with IERP Replay packet as shown in the Fig. 6 and reply packet is shown in Fig. 6(a).

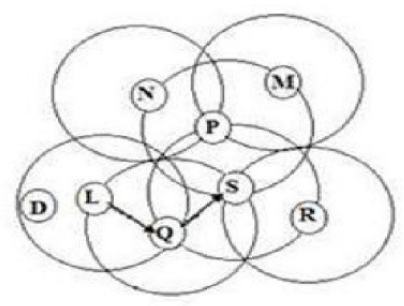

Fig. 6: IERP Reply Transmission

\begin{tabular}{|c|c|c|c|c|}
\hline DN & SN & Intermediate BN & Packet Type & BH \\
\hline D & S & L, Q & REP & 2 \\
\hline
\end{tabular}

Fig. 6(a): IERP reply packet format of Fig-6 
In this Selective bordercasting approach the IERP Request packet's must save discovered routing information in a buffer for awhile and if there are requests for the same destination which the IERP REQ's are sent by nodes in the previous search. For example, when a destination moves inside the routing zone of Q, as shown in the Fig. 7, the previous recorded route information stored in the node Q and L, the node Q will generate the Reply packet to source $\mathrm{S}$.

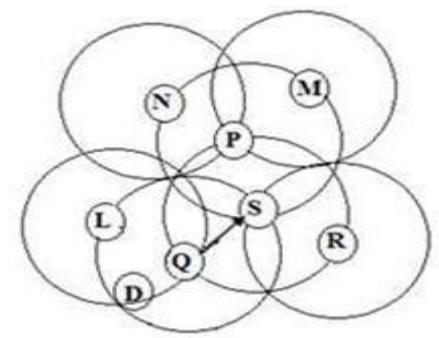

Fig. 7: a case when the destination node moves inside the zone.

In the case of destination which moves outside the zone of $\mathrm{L}$ as shown in the Fig. 8, it has no route to destination which is required for the query source, and then a new search is started from the node $\mathrm{L}$.

(D)

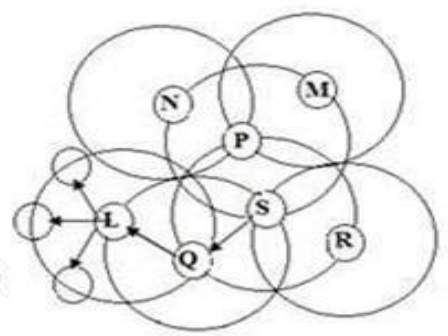

Fig. 8: A case when DN moves outside the zone

Thus the number of IERP Route Request packets is reduced, because the route reconfiguration is started from the destination failure reporting node instead of beginning from the source. Hence this reduces control overhead packets and end-to-end delay time, which results in higher throughput.

\section{A. Algorithms}

Nomenclature: $\mathrm{n}=$ number of nodes, $\mathrm{b}_{\mathrm{k}}$ and bf are band- width and buffer values of the base station. Algorithm 1: Main program

Begin

Initialize the nodes in network layer

2 Call ZRPInit

2 Call ZRP Router function

2 Call ZRP Finalize

End.

Algorithm 2: ZRP Init

Begin

2 Initialize the nodes with ZRP initialization

2 If (IARP/IERP/MDVZRP/SBZRP) are running

- Display error message -

Disable the initialization

2 else 
International Journal of Wireless \& Mobile Networks (IJWMN) Vol. 3, No. 4, August 2011

- If (MDVZRP is enabled)

a Register ZRP with MDVZRP

a Call MDVZRP

Init - else

a Register ZRP with IARP

a Call standard IARP Init

a Register ZRP with IERP

a Call standard IERP Init

Register ZRP callback Functions

Initialize statistics variables

Stop

End.

Algorithm 3: MDVZRP Init

Begin

2 Node enters MDVZRP Initialization

2 Initialize private data structure

2 Read zone radius

2 Initialize the routing table

2 Read user statistics

2 Schedule timer

2 Stop; End.

Algorithm 4:ZRP Router function

Begin

2 If MDVZRP is initialized already then Call MDVZRP Router function

2 Else initialize standard IARP Router function

2 If packet is not routed then Call standard IERP router function

2 Stop;

End.

Algorithm 5:MDVZRP Router function

Begin

2 Enter Router function

2 Check for route in the table

2 If route available

- Send packets to next layer

- If error occurs display error message -

Ask for retransmission

2 else

- Initialize the broadcast with destination address

- Find the routing information

- Update the routing table

2 Stop; End.

Algorithm 6: ZRP Finalize

Begin

2 If node enters MDVZRP Initialization then call

MDVZRP Final standard

2 If node enters SBZRP Intialization then call

IARP/IERP/BRP Final standard

2 If node enters QCS Initialization then call

IARP/IERP/QCS Final standard

2 Stop;

End. 


\section{SIMULATION}

\section{SIMULATION RESULT}

In this section the methodology is presented .This methodology is used in order to isolate the impact on network performance. We used a well known network simulator QualNet version 5.0.

\section{Simulation Platform, Models and Attributes}

The image of the network as it appears in QualNet version 5.0 is presented in Fig. 9

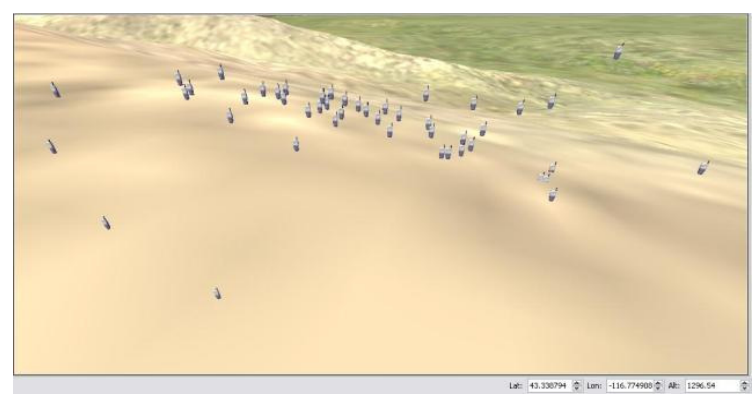

Fig. 9: Topology of the Simulated Network on an Urban Terrain

The physical medium used is the well known 802.11DSSS PHY with a data rate of 2 mbps. The MAC protocol used is $802.11 \mathrm{MAC}$ protocol, configured in a MANET mode on an urban terrain. More precisely we use only Distributed Coordination Function (DCF) of the protocol.

\section{Results}

Table-1 shows parameters we considered for simulations. Table 1

Parameters we considered for simulations.

\begin{tabular}{|c|c|}
\hline Parameters & Values \\
\hline Routing Protocol & ZRP and Enhanced ZRP \\
\hline Fading Model & Rayleigh \\
\hline Shadowing Model & Constant \\
\hline Pathloss Model & Cost-231 HATA \\
\hline Energy Model & Mica Motes \\
\hline Battery Model & Simple linear \\
\hline Terrain File & DEM \\
\hline Mobility Speed & 15 to 20 meter/sec \\
\hline Network Size-10-20 nodes & Area Considered-500 X 500 \\
\hline Network Size-50-100 & Area Considered-1000 X 1000 \\
\hline Network Size-200 nodes & Area Considered-3000 X 3000 \\
\hline Node Placement & Random node placement under \\
\hline
\end{tabular}

\section{Simulation Model}

Different scenarios with different node density are considered to observe the cumulative behavior of SBZRP, MDVZRP, QCS over the enhanced ZRP using QUALNET wireless simulator. Mobility speeds of $15-20$ meter/sec is considered, with network nodes varying from 10-100 nodes, size of 500-3000 meters. Following are the simulation models embedded. 
International Journal of Wireless \& Mobile Networks (IJWMN) Vol. 3, No. 4, August 2011

2 Fading model:Rayleigh

Shadowing model:Constant

Path loss model:Cost-231 HATA

Battery model:Simple linear

2 Energy model:Mica Motes

2 Mobility model:Random way point

C. Simulation Procedure

2 Generate topology consisting of wireless nodes.

2 Initialize all simulation models.

2 Define source and destination.

2 Build the Routing algorithm.

2 Evaluate the performance parameters.

\section{Performance parameters}

2 Throughput: It is the total number of bits that are received at the receiver.

2 Efficiency: It is the ratio of number of packets sent to the number of packets received.

2 Convergence time: It is the total time taken to and the destination route.

2 Overload transmission: It is the ratio of control packets received to the total packets received.

\section{RESULTS}

The figure shows better throughput upto 25 nodes, further increase in the nodes decreases the throughput. Compared ZRP results enhanced ZRP outputs are better, hence our algorithm performance better. The efficiency of the enhanced ZRP is more compared to the ZRP in our scheme. As the overhead packets are reduced, hence the information packet reception becomes more. Hence there is increase in the efficiency in turn system performance also.

In figure 12 , it is clearly shows the time required for route convergence is comparatively less for enhanced ZRP protocol then the ZRP. With specific route specification, it becomes faster for sending the route rather than dealing along with general specification. The time required for last packet received is done to analyze the delay on to the route. The enhanced ZRP protocol requires less time than the standard ZRP. This is shown in figure 13. The overhead transmission is

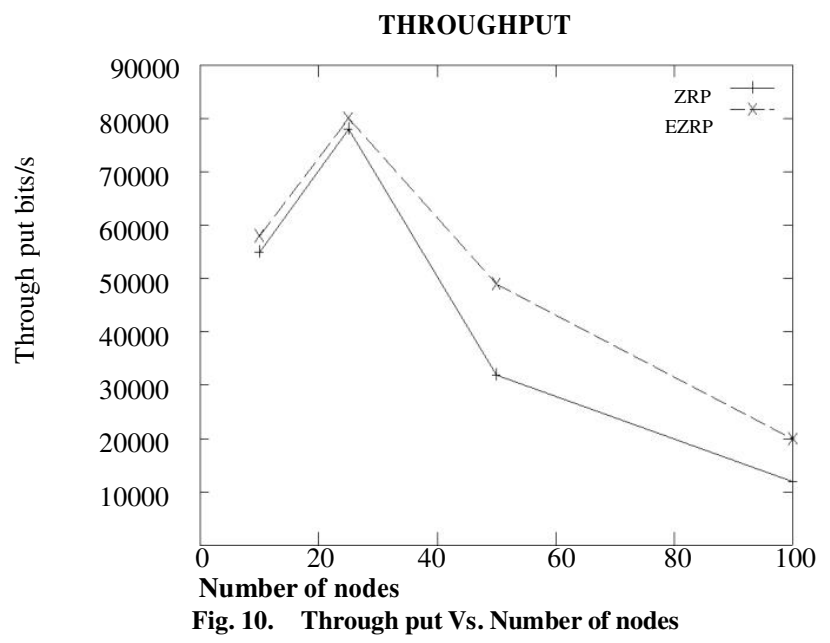


International Journal of Wireless \& Mobile Networks (IJWMN) Vol. 3, No. 4, August 2011

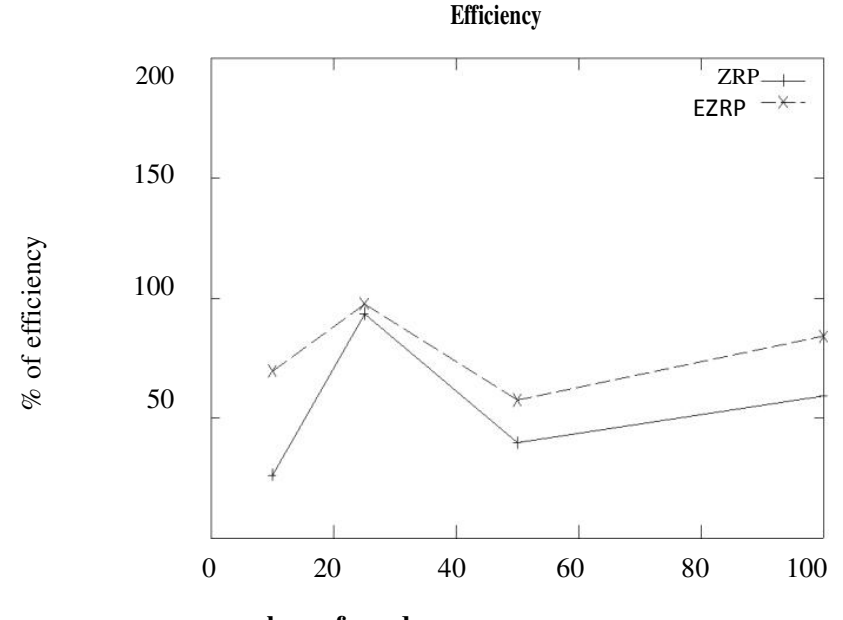

number of nodes

Fig. 11 Efficiency Vs. Number of nodes

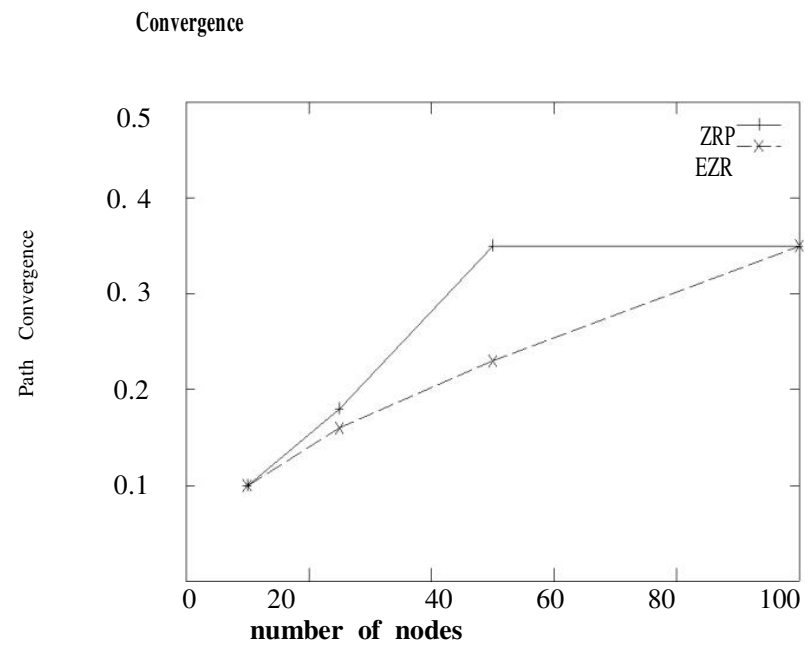

Fig. 12 Convergence time Vs. Number of nodes.

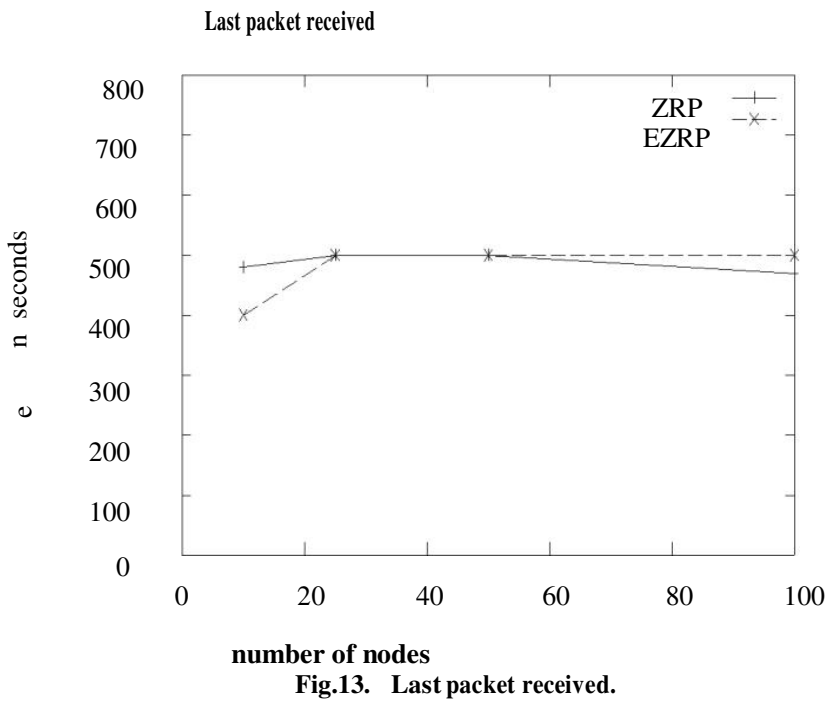




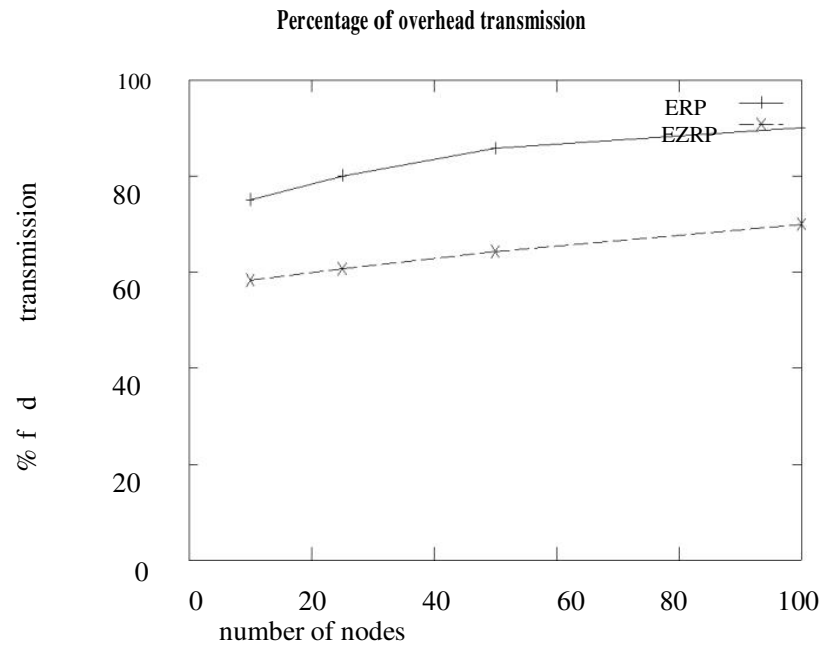

Fig. 14. Percentage of Overhead transmission Vs. Number of nodes.

\section{CONCLUSIONS}

Our proposed query control schemes exploit the structure of the routing zone to provide enhanced detection and prevention of overlapping queries and thus improve delay and overhead due to control traffic. The techniques can be applied to single or multiple channel MANETs to improve both the delay and control traffic performance of ZRP. In this scheme, we allow ZRP to provide routes to all accessible network nodes, with less control traffic than purely proactive link state or purely reactive route discovery, and with less delay than conventional aodv searching. The protocol provides less control overheads including path in the Ad-hoc networks, which improve the system efficiency and also the system performance. Extensive simulation results reveals that our scheme features better transmission delay, route convergence time, the last packet reception time, system efficiency and system through-put. Our scheme can be extended to provide good QoS. By considering other parameters such as buffers, bandwidth etc. Further simulation can be carried out by considering mobility and applying dynamic cluster formation with respect to wireless nodes.

\section{REFERENCES}

[1] Zygmunt J. Haas and Marc R. Pearlman, The Performance of Query Control Schemes for the Zone Routing Protocol IEEE/ACM Transaction on Networking, Vol.9, No. 4, PP. 427-438, August 2001 .

[2] Leonard Barolli, Yoshitaka Honma, Akio Koya, Arjan Durresi and Junpei Arai, A Selective Border-casting Zone Routing Protocol for Ad-hoc Networks, Proceedings of the 15th International Workshop on Database and Expert Systems Applications (DEXA04), PP. 326-330, 2004.

[3] Idris Skloul Ibrahim, A.Etorban and Peter J.B King, Multipath Distance Vector Zone Routing Protocol for Mobile Ad-Hoc Networks MDVZRP, PGnet, John Moores University, PP. 171-176, July 2008.

[4] Prince Samar, Marc R. Pearlman and Zygmunt J. Haas,Independent Zone Routing:An Adaptive Hybrid Routing FrameWork for Ad hoc Wireless Networks",IEEE/ACM Transaction On Networking,Vol.12, No.4, PP. 595-608, August 2004.

[5] E.M. Royer and C.K. Toh,A Review of Current Routing Protocols for Adhoc Mobile Networks",IEEE Personal Communications, Vol. 6, No.2 PP.46-55, 1999.

[6] P. Papadimitratos and Zygmunt J. Haas, Secure Message Transmission in Mobile Ad hoc Networks",Journal Elsevier Ad hoc Networks, Vol. 1, No.1 PP. 193-209, 2003. 
International Journal of Wireless \& Mobile Networks (IJWMN) Vol. 3, No. 4, August 2011

[7] Panagiotis Papadimitratos, Zygmunt J. Haas, Secure data communica-tion in mobile ad hoc networks". IEEE Journal on Selected Areas in Communications Vol. 24, No. 2, PP. 343-356, 2006

[8] Panagiotis Papadimitratos, Zygmunt J. Haas, Emin Gn Sirer, Path set selection in mobile ad hoc networks", Proc. of the 3rd ACM international symposium on Mobile ad hoc networking computing MobiHoc, PP.1-11,2002

[9] K. Sanzgiri, B. Dahill, B. N. Levine, C. Shields, and E. Belding-Royer.”A Secure Routing Protocol for Ad Hoc Networks." In Proc. IEEEInternational Conference on Network Protocols, PP.78-87, 2002

[10] K. Sanzgiri, B. Dahill, B. N. Levine, C. Shields, and E. Belding-Royer"Authenticated routing for ad hoc networks," IEEE J. Select. AreasCommun., Vol. 2, No. 1, March 2005.

[11] Ming Yu and Kin K. Leung, "A trustworthiness-based QoS routing protocol for wireless ad hoc networks", IEEE Transactions on Wireless Communications, Vol. 8, No. 4, April 2009.

[12] Moitreyee Dasgupta, S. Choudhury and N. Chaki," Routing Misbehavior in Ad Hoc Network", International Journal of Computer Applications, Vol.1, No. 18, PP.89-92, 2010

[13] Kavita Taneja and R.B.Patel," Mobile Ad hoc Networks: Challenges and Future”, Proceedings National Conference on Challenges and Opportu-nities in Information

Technology, RIMT-IET, Mandi Gobindgarh, PP.133-135, March 3, 2007.

[14] J. Broch et al., "A Performance Comparison of Multihop WirelessAd Hoc Network Routing Protocols,” Proc. IEEE/ACM MOBICOM'98, pp. 85-97, Oct. 1998.

[15] C. Perkins, E.M. Royer, S.R. Das, and M.K. Marina, "Performance Comparison of Two On-demand Routing Protocols for AdHoc Networks,” IEEE Personal Communications, pp. 16-28, Feb.2001.

[16] S. Singh, M. Woo and C. S. Raghavendra, "Power aware routing in mobile ad hoc netwo rks”, IEEE/ACM MobiCom-98, pp. 181-190. Oct.1998.

[17] VincentD. Park and M. Scott Corson, "Adhoc On demand Distance Vector(AODV)version4:Functional specification,"Internet- Draft,draft-ietfmanet- AODV-spec04.txt, July 2001.

[18] D. Johnson, D. Maltz and Yih-Chun Hu, "The Dynamic Source Routing Protocol for Mobile Ad Hoc Networks," http://www.ietf.org/internet- drafts/draftietfmanet- DSR-09.txt, IETF Internet draft, Apr. 2003.

\{ 19$\}$ B. Rajagopolan and M. Faiman, A new responsive distributedshortest-path routing algorithm, $A C M$

Comp. Commun. Rev.19(4) (1989).

[20] .J. Garcia-Luna-Aceves, Loop-free routing using diffusingcomputations, IEEE Trans. Networking $1(1)$ (1993).

[21] McQuillan, Adaptive routing algorithms for distributed computer networks, BBN Rep. 2831, Bolt Beranek and Newman Inc., Cambridge,MA (1974).

[22] J.J. Garcia-Luna-Aceves, Distributed routing with labeled distances, Proc. IEEE INFOCOM'92 ,Florence,

Italy, 1992.

[23] J.J. Garcia-Luna-Aceves, Steady-state response of shortest-path routing algorithms, 11th Annual Int.

phoenix Conf. on Comp. and Commun., Scottsdate, AZ, 1992.

[24] B. Awerbuch, Shortest-paths and loop-free routing in dynamicnetworks, Comp. Commun. Rev. 20(4) 1990).

[25] E. Dijkstra and C. Scholten, Termination detection for diffusing computations, Inform. Process. Lett. 11(1) (1980).

[26]E. Gafni and D. Bertsekas, Distributed algorithms forgenerating loop-free routes in networks with frequently changing topology, IEEE Trans. Commun. (January 1981).

[27] M. Weber (Bates) and A. Ephremides, A simulated performance study of some distributed routing algorithms for mobile radionetworks, Proc. Johns Hopkins Conf., Baltimore, MD, 1983

.[28] M.S. Corson and A. Ephremides, A distributed routingalgorithm for mobile radio networks, Proc. 1989

IEEE Military Communications Conf., Boston, MA, 1989.

[29] A. Ephremides, J. Wieselthier and D. Baker, A design concept for reliable mobile radio networks with 
International Journal of Wireless \& Mobile Networks (IJWMN) Vol. 3, No. 4, August 2011

frequency hopping signaling, Proc. IEEE (January 1987).

[30] B.S. Manoj, C. Siva Ram Murthy, Real-time traffic support for ad hoc wireless networks, in: Proceedings

Of IEEE ICON 2002, August 2002, pp. 335-340.

\section{Author Details}

Dr. Jithendranath Mungara received M.Tech and Ph.D (Andhra University), India. He has served as Principal, BTLIT, Bangalore and currently working has Dean Research and Director PG Studies in Computer Science Department, CMRIT, Bangalore.

He has teaching experience more than a decade and also served as Engineer in prestigious Boeing Industry, U.S.A and other Software

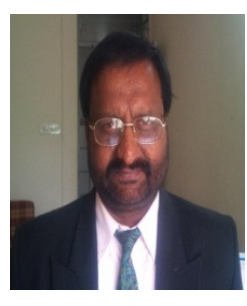
Companies. He has Organized Several National and International Workshops and conferences.

His research interest includes MANETS, Sensor Networks, Cloud Computing etc.

M.N Sree Ranga Raju received B.E Degree (Bangalore University) in 1985 and M.Tech (Mysore University) in 1991, India. He is currently a research scholar in VMU, Salem, Tamilnadu, India. He has served as Professor and Head of the Department of Telecom Engg, BIT, Bangalore .

He has a teaching experience more than two and half decades. He has

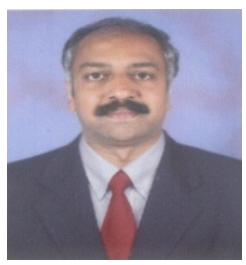
Organized Several National Workshops and conferences.

His research interest is in the areas of Networking and Wireless Mobile systems. His reaseach has focussed on design of routing protocols, Mobility modelling, and its effects on link characteristics for performance optimisation in MANETS. 